\title{
Microcontroller ATmega8535 Based Solar Tracker Design for PV System Applications in Equator Region
}

\author{
Syafaruddin $^{1 *}$, Ranu Fauzan ${ }^{1}$, Andika S. Amir ${ }^{1}$ and Hajime Miyauchi ${ }^{2}$ \\ ${ }^{1}$ Department of Electrical Engineering of Universitas Hasanuddin, 90245 \\ Tamalanrea-Makassar, Indonesia \\ 2Department of Computer Science and Electrical Engineering of Kumamoto \\ University, 2-39-1 Kurokami, Kumamoto 860-8555, Japan \\ *syafaruddin@unhas.ac.id; ranu.fauzan@ap.jll.com;andika_uh10@yahoo.com; \\ miyauchi@cs.kumamoto-u.ac.jp
}

\begin{abstract}
In order to be effectively utilizing the sunlight energy into electricity, the photovoltaic modules should be perpendicularly to the sunlight direction. However, the orientation of sunlight on Earth's surface is varied that makes it difficult to find the optimal direction. For this reason, the solar tracker should be available to drive modules in the expected direction. In this study, the solar tracker is designed based on microcontroller ATMega8535 and the position is adjusted based on the IC RTC timer response. The IC RTC is able to regulate the movement of photovoltaic modules about 15 degree per hour. The updating position of $P V$ module is constantly changed, but the approach is enough for capturing sunlight energy for $P V$ applications in equator region. The testing results show that the accumulative energy capturing annually from a $2250 \mathrm{Wp}$ of PV system is about $500 \mathrm{kWh}$ higher than that of without solar tracker.
\end{abstract}

Keywords: Solar tracker, microcontroller, real-time clock, actuator parabola, PV system

\section{Introduction}

The promising of huge sunlight intensity arriving on Earth leads to increase the penetration level of solar energy in the electricity utilization. Nevertheless, photovoltaic (PV) systems have its own challenges in terms of increasing system flexibility and efficiency. It is due to the nature characteristics of irradiance which are non-linear, random and affected by other climate phenomena, such as wind speed, ambient temperature and cloudy condition. Consequently, it causes to fluctuating the output power of PV module/cell. This problem arises when integrating the PV modules with other devices, such as battery and controller. In this respect, it is necessary to predict accurately the daily irradiance in order to optimize such devices [1-3]. Another challenge is the characteristics of material composing PV cell, which are also non-linear. Each solar cell material shows different response to the wavelength of sunlight intensity. For example, in commercial Silicon solar cells, if the temperature is kept constant, open circuit voltage and short circuit current increases logarithmically and linearly with increased sunlight, respectively. On the other hand, if the temperature increases, the diffusion voltage within the $\mathrm{p}$-n-junction is reduced that makes relatively strong decreasing open-circuit voltage by approximately $-2 \mathrm{mV} /{ }^{\circ} \mathrm{C}$. Under the same assumption, the short-circuit current increases by approximately $0.0006^{\circ} \mathrm{C}^{-1}$ due to the enhanced mobility of charge carriers within the semiconductor [4]. These kinds of physical characteristics are being improved by 
reducing the negative temperature-voltage coefficient of non-crystalline Silicon solar cells materials [5].

The increase in penetrating of PV system technology is still limited due to the high cost of module and encapsulation, and the low energy conversion efficiency. The utility and household are showing resistance to install PV system because of these two factors. The high cost of module comes from the manufacturing process of Silicon material from ingot separation to the cell crystal built-up requires high temperature by means high energy consumption. Consequently, the energy payback of Silicon solar cell is around five years. In addition, the production cost is more added by the material encapsulation. The high cost of crystalline Silicon is alleviated by proposing other materials such as amorphous Silicon and thin-film Silicon. However, the efficiency energy conversion is lower than the conventional mono- or poly-crystalline Silicon technology. On the other hand, the high efficiency is targeted by introducing tandem solar cell from Copper Indium Diselenide (CIS), Galium Arsenide (GaAs) and Cadmium Telluride (CdTe) materials. However, the high cost is inevitable for such new solar cell materials and they are still rarely found in the commercial level. This is not about discouraging of new technology of solar cell because the new proposed materials will get mature in terms of cost reduction and high efficiency conversion after the gained experience in the laboratory and the field of applications in the near future [68].

In the meantime, while preceding the contributions in the field of materials science, the studies in the optimal operation PV systems must be kept on to increase the efficiency of the system. This paper aims to find the optimal operating point by means the capturing of maximum output power and energy with low operational cost. However, it is not a trivial problem due the weather conditions and surrounding obstacles that cause complicated powervoltage characteristics of PV arrays. The global maximum power point shifts when the irradiance and ambient temperature change during the day. When a constant voltage is set as a reference signal for conventional controller, the output power is potentially lower than the optimum power. This condition is made worst under partially shaded conditions where the global maximum power point may shift far away from the initial setting of controller [9]. There are so many proposed methods to overcome such problems, commonly known as the maximum power point tracking (MPPT) controller [10], [11]. In this respect, the MPPT controller can be defined as the state of art technique to obtain the maximum output power of photovoltaic system.

In general, the MPPT controller can be categorized into electronically and mechanically based methods. The main idea of electronically based MPPT controller is how to drive the voltage or current of power electronic converter devices without any moving part. Basically, under uniform irradiance conditions, almost all conventional MPPT controllers can respond quite accurately. However, it is very difficult to find the optimum power point under nonuniform irradiance conditions. Wide ranges of methods from numerical, statistical and intelligent techniques have been listed in [12]. In that manner, the main objective is actually to improve the tracking accuracy by using simple and high efficiency methodologies. On the other hand, the mechanically based MPPT controller is based on the mechanical design to drive the PV modules perpendicular towards the sunlight direction. In the design of solar tracker, there will be moving parts of PV module structure by motor rotation [13]. The solar tracker is not only used in the PV generation system, but also already used to drive the heliostat in the solar thermal tower applications [14-16].

In the implementation level, there are several types of solar tracker; polar tracker, horizontal axis or single tracker and vertical axis tracker [17]. Polar trackers have one axis parallel to the axis of Earth rotation along the north and south poles. Polar tracker is often 
combined with timer, because the maximum performance is highly desirable in the evening, especially for grid connected PV systems application. Meanwhile, the horizontal axis has horizontal axis rotation for single axis tracker mounted on horizontal position to the ground. Both ends of the axis rotation in the horizontal axis tracker can be used also by other types of tracker for lower installation costs. This type of tracker is less effective for areas located at higher latitudes. However, the main advantage is the inherent robustness and simplicity of the mechanism of the supporting structure. On the other hand, the vertical axis tracker has the axis rotation to the vertical axle tracker. The tracking direction is from east to west during the day. The vertical axis tracker is more effective at high latitudes than the horizontal axis trackers. In this paper, the solar tracker is designed based on microcontroller IC ATMega8535 and the position is adjusted based on the IC RTC timer response. The IC RTC is able to regulate the movement of PV modules about 15 degree per hour. The use of IC timer is end up to similar design with the horizontal axis tracker. The supported components of design system are simpler and more flexible. Therefore, the proposed design are modest and focused on the maximizing the output power of PV system [18]. The detailed system configuration of the proposed method is explained as follows.

\section{Configuration of the Proposed Design}

\subsection{Determination of angle movement of solar tracker}

The particular interest regarding to the determination of angle movement of solar tracker is the daily pattern of sun movement. The sun rises in the east, then reaches solar noon before set somewhere in the west [19]. The solar noon is the highest elevation of sun in the sky, which depends on the local latitude of location (L) and solar declination $(\delta)$. The solar noon angle or altitude angle maximum can be calculated as follows:

$$
\beta_{N}=90^{\circ}-L+\delta
$$

where $\mathrm{L}$ is positive in the northern hemisphere and negative for southern hemisphere.

The solar declination angle is the line latitude where the sunlight arrives on certain location in particular day of the year. Therefore, the solar declination is depending on the day number (n), for example $n=1$ is for January 1 , and $n=365$ is for December 31 . The equation can be expressed as follows:

$\delta=23.5 \sin \left[\frac{360^{\circ}}{365^{\circ}}(n-81)\right]$

Equation (2) implies that the solar declination varies sinusoidal between $\pm 23.5^{\circ}$ on the day number 81 . In the calendar, the day number of 81 is the spring equinox, March 21 where the sun is exactly over the equator. In the Northern hemisphere, the highest point of solar noon on the summer solstice (June 21) is $\beta_{N}=90^{\circ}-L+23.5^{\circ}$; while the highest point of solar noon on the winter solstice (December 21) is $\beta_{N}=90^{\circ}-L-23.5^{\circ}$. 


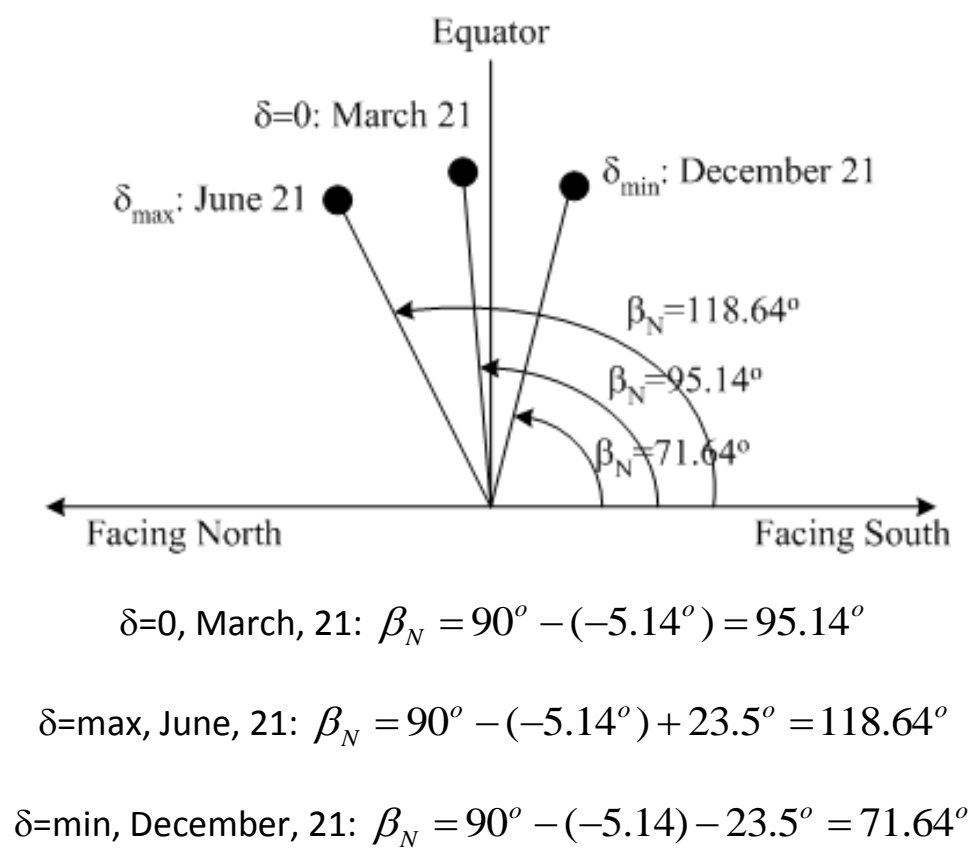

Figure 1. The pattern of solar noon in our study location

In this study, we are designing solar tracker for PV application in equator region. The local latitude of our city, Makassar, South Sulawesi of Indonesia is located 5.14 ${ }^{\circ}$ SE. Based on (1) and (2), the maximum solar noon can be shown in Figure 1. It can be seen that the solar noon deviates not too far away from the equator. It means that the quality of sunlight intensity can be guaranteed good annually. Therefore, we do not have such kind of summer or winter solstice in equatorial region. The only need for operating the solar tracker in this region is to manually adjust the module either facing North or South, which can be done every six months.

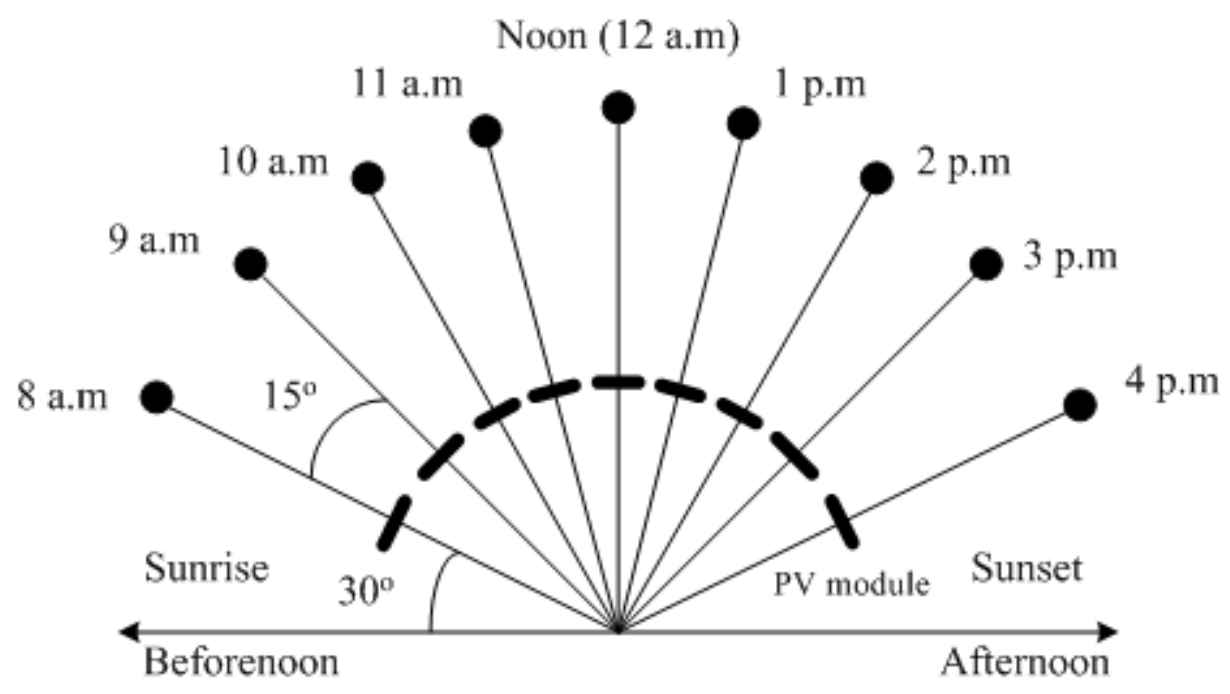

Figure 2. Position of module based on solar tracker adjustment 
In addition, it is important to determine how much the angle of designed solar tracker is required to drive the PV module for perpendicular to the direction of sunlight. If we assume the solar noon at 12 p.m and the initial angle at 8 a.m is $30^{\circ}$, then every hour the angle of solar tracker should be updated every $15^{\circ}$. This variation is depicted in Figure 2. After the module reaches the position at 4 p.m, control mechanism is applied to reset the solar tracker to the position similar to $8 \mathrm{a} . \mathrm{m}$. It means that the angle of PV module turns back to $30^{\circ}$ and waits for the next day operation.

\subsection{Materials and components for solar tracker design}

There are several types of solar tracker in the implementation level either for PV applications or heliostat based solar thermal applications. They can be categorized active and passive with single axis or dual axis. For single axis tracker, there is one rotational axis which can be freely moved. This kind of design is usually parallel with North meridian in order to possible synchronism to cardinal direction using sophisticated tracking algorithm. To increase the efficiency of the system, the single tracker is sometimes accompanied by polar mount, elevation guidance which depends on the regular interval every year. On the other hand, dual axis tracker has two freely movement rotational axis where they are normal positioned each other. The type of dual axis trackers are polar and altitude-azimuth tracker.

Table I. Materials and components for solar tracker design

\begin{tabular}{|c|c|}
\hline Material and components & Amount \\
\hline Photovoltaic module $50 \mathrm{~W}_{\mathrm{p}}$ & 2 \\
\hline Actuator parabola $12 \mathrm{~V}$ & 1 \\
\hline Support tilt & 2 \\
\hline Cable NYY $2 \times 1.5 \mathrm{~mm}^{2}$ & $30 \mathrm{~m}$ \\
\hline DT-AVR low cost system minimum & 1 \\
\hline DT-IO I2C peripheral & 1 \\
\hline PCB board & 1 \\
\hline Relay 12VDC & 2 \\
\hline Transistor TIP122 & 2 \\
\hline Diode IN4004 & 2 \\
\hline LED & 2 \\
\hline Resistor 1K $\Omega$; 1Watt & 2 \\
\hline LCD 16x2 & 1 \\
\hline Battery 12Vdc 100Ah & 1 \\
\hline Header and Black Housing 10 pin & 3 \\
\hline Rainbow (Colored) Cable & $2 \mathrm{~m}$ \\
\hline DT-H1Q AVR USB ISP & 1 \\
\hline Laptop Acer & 1 \\
\hline Voltmeter DC & 2 \\
\hline Amperemeter DC & 2 \\
\hline Resistive load $90 \Omega \max .2700 \mathrm{~W}$ & 1 \\
\hline Degree measurement tool & 1 \\
\hline
\end{tabular}

The proposed design is actually single axis tracker with horizontal axis with the ground. This type is not so effective for high latitude, but very reasonable for equatorial region. Another advantage is the strength of structure with simple mechanism. In addition, because of 
horizontal panel position, number of panels can be installed without potentially shading occurs on module. In order to increase the movement mechanism, control action can be performed to drive group of module. In our design, we improve the horizontal axis tracker with IC timer combined simple microcontroller performance. The proposed approach is ideal for equator region; including Indonesia where the sunlight pattern is less varied from time to time annually. For designing of our proposed solar tracker, some materials and components are provided and listed in Table I.

The schematic diagram of the proposed solar tracker design is shown in Figure 3. It can be seen that the IC RTC, ATmega8535 and LCD are supplied by voltage of Vcc (5 Vdc), while the motor driver circuit is supplied by $12 \mathrm{Vdc}$. The IC RTC is the IC timer where the output parameters, such as date and time can be displayed in LCD. Meanwhile, the microcontroller ATmega8535 translates the developed program from Codevison AVR software to make the IC timer output as the input reference controller. The reference means the base of microcontroller in giving instruction to motor driver to rotate the actuator parabola. Consequently, the movement of actuator will push and pull the PV module to the intentional direction. When the appropriate module position is reached, the limiter switch will activate to give instruction to the microcontroller to stop the movement. Once the PV module stops in each angle, the output characteristic is measured. The detailed specification of each component is explained as follows by including the hardware and software design.

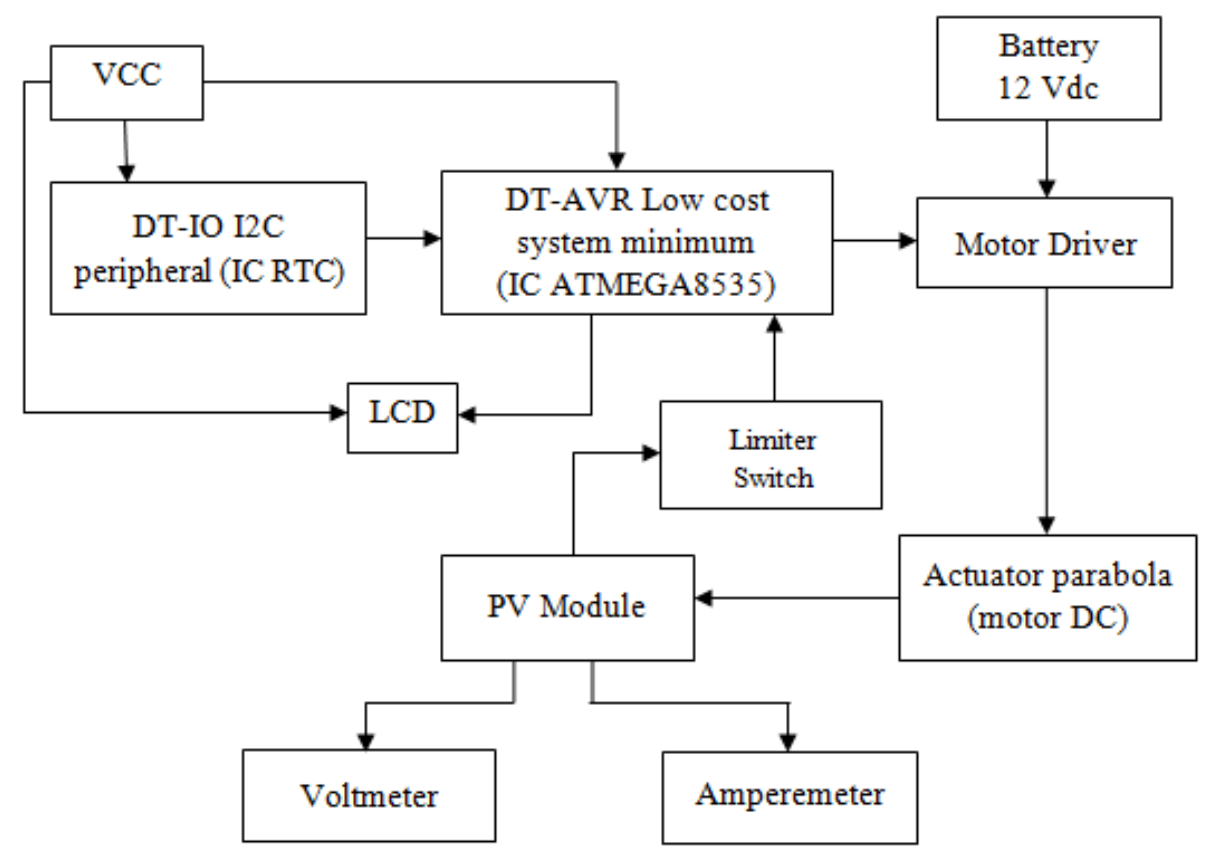

Figure 3. Schematic diagram of our designed solar tracker

\subsubsection{IC Real Time Clock (IC RTC)}

Real Time Clock is basically correlated with time output from seconds to hours and from date to year. Another function is the IC RTC can be used to store permanent data in the internal RAM RTC, because the data cannot be loosed although the power supply is disconnected. It is due to the battery embedded in the IC system to power the clock all the 
time. Beside this, the IC RTC also can be used as the timer and alarm. For time output calculation, this device is valid up to 2100 year with mode selection either 12 or 24 hour clock with a.m and p.m in 12 hour mode.

Electronically, the IC RTC DS1307 utilizes I2C technique with capability of 2 paths of transferring serial data in compared with 3 paths in SPI and MicroWire techniques. All techniques have basically one path for clock. The remaining 1 path in $\mathrm{I} 2 \mathrm{C}$ has the capability of bidirectional data transfer, while the 2 paths of SPI and MicroWire have only capable in single directional of input-output data transfer. The protocol communication of I2C in RTC DS1307 is similar to the access EEPROM serial type of 24C04. The mechanism is sending start-bit, address of RTC ( $0 \mathrm{xC} 0)$ with bit $\mathrm{R} / \mathrm{W}$ low then the register number is willing to be accessed.

The feature of IC RTC DS1307 as shown in Figure 4 is listed as follows:

- Real-time clock (RTC) can save data time from seconds to hours and from date to year up to 2100 year.

- 56-byte, battery-backed, RAM nonvolatile (NV) RAM for memory storage

- Serial interface of two-wire (I2C)

- The output signal is the programmable square-wave

- Automatic detection of loss input power and failure in the switch circuit

- Power consumption is with current is less than 500nA (mode of backup battery with operational oscillator)

- Industrial feature with temperature range between $-40^{\circ} \mathrm{C}$ and $+85^{\circ} \mathrm{C}$

- Available in 8-pin DIP or SOIC

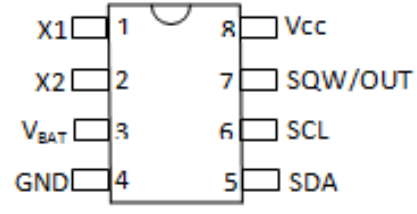

DS1307 8-Pin DIP (300-mil)

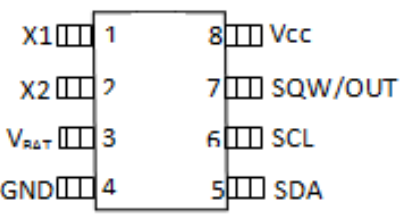

DS1307 8-Pin SOIC (150-mil)
- $\mathrm{V}_{\mathrm{CC}}$ - Primary power supply

- $\mathrm{X} 1, \mathrm{X} 2$ - 32.768kHz Crystal connection

- $\quad$ VBAT - +3V Battery input

- GND - Ground

- $\quad$ SDA - Serial data

- $\mathrm{SCL}$ - Serial clock

- SQW/OUT - Square wave/Output driver

Figure 4. Diagram of PIN IC RTC DS1307 


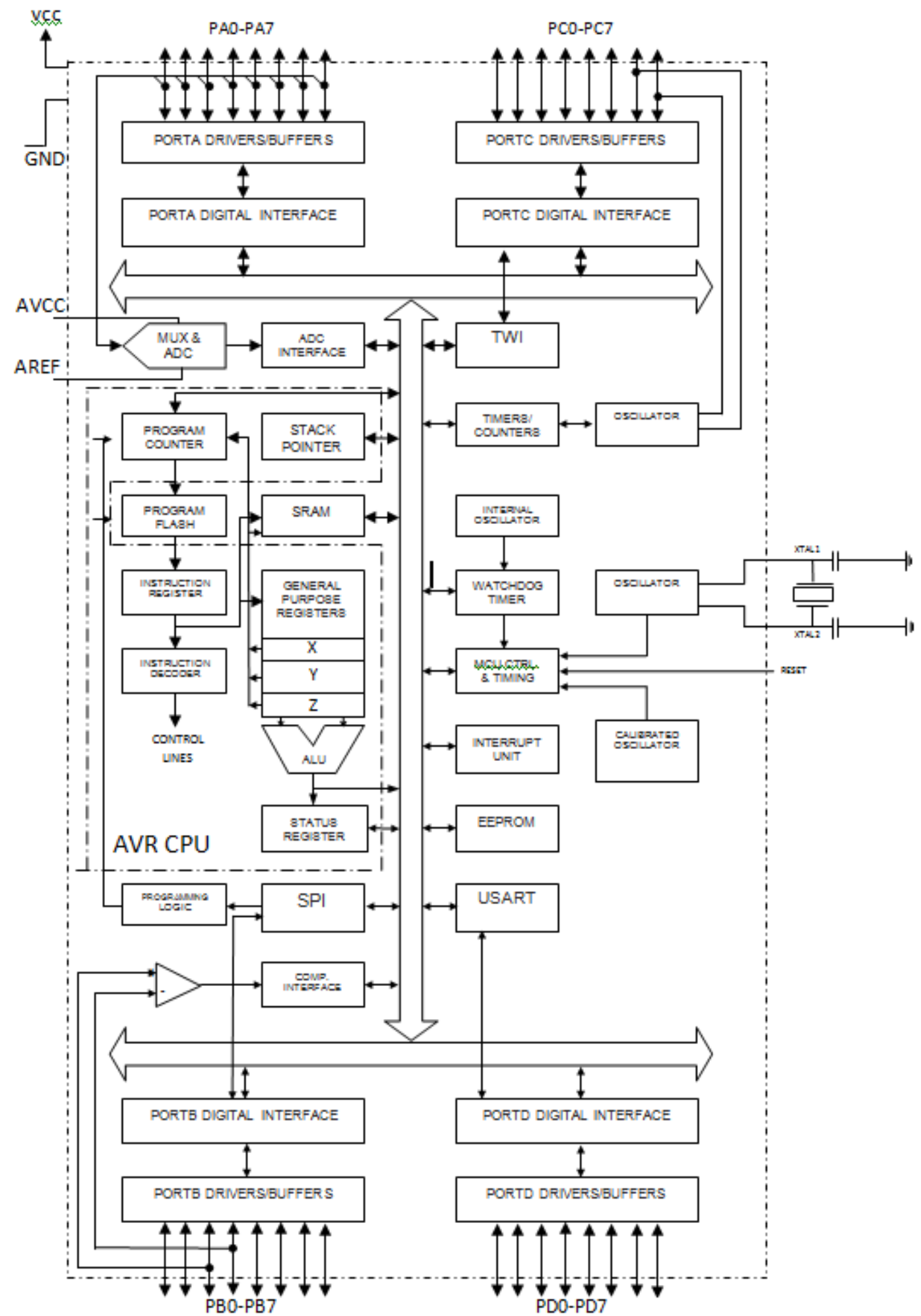

Figure 5. The complete architecture of microcontroller IC ATmega8535 


\subsubsection{Microcontroller of IC ATmega8535}

In the proposed design, the controller is merely performed by AVR microcontroller of IC ATmega8535. The controller architecture has RISC 8 bit, where all instructions are put in 16 bit code (16 bits words) and most instructions are executed in 1 cycle clock. The execution time is completely different with MCS51 based instruction which requires 12 cycle clock. Of course, the architecture of AVR and MCS51 microcontrollers are totally different. The AVR microcontroller uses Reduced Instruction Set Computing (RISC) technology, while MCS51 is based on Complex Instruction Set Computing (CSIC) technology.

In general, the AVR microcontroller can be grouped into ATtiny, AT90Sxx, ATMega and AT86RFxx. The basic difference amongst them is the memory, peripheral and its function, although the architecture and instruction are almost the same. The complete architecture and the pin configuration of microcontroller ATmega8535 are shown in Figure 5 and Figure 6, consecutively. The capability of ATmega8535 is listed as follows:

- Microprocessor system based RSIC is 8 bit with maximum speed $16 \mathrm{MHz}$

- Flash memory capability is $8 \mathrm{kB}$, SRAM 512 byte and EEPROM 512 byte.

- Internal ADC with fidelity about 10 bit per 8 channel

- Serial communication port (USART) with the maximum speed 2.5 Mbps

- Sleep mode with 6 selections to save electrical energy consumption.

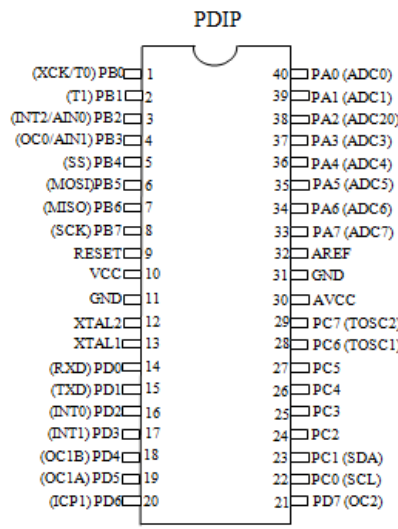

Remarks:

- $\quad$ VCC is the pin for the input power

- GND is the pin for ground

- Port $A$ (PAO to PA7) is the pin for bidirectional $I / O$ and input for $A D C$

- Port $\mathrm{B}$ (PBO to PB7) is the pin for bidirectional $\mathrm{I} / \mathrm{O}$ with special functions, such as timer, analogue comparator and SPI

- Port C (PC0 to PC17) is the pin for bidirectional I/O with special functions, such as TWI, analogue comparator and timer oscillator

- Port D (PD0 to PD7) is the pin for bidirectional $\mathrm{I} / \mathrm{O}$ with special functions, such as analogue comparator, external interruption and serial communication

- RESET is the pin to reset the microcontroller

- XTAL1 and XTAL2 is the pin for the external clock

- $A V C C$ is the pin for the ADC input voltage

- $A R E F$ is the pin for the $A D C$ voltage reference

\section{Figure 6. The pin configuration of microcontroller IC ATmega8535}

Another important feature of AVR microcontroller ATmega8535 as shown in Figure 7 is the memory map with file register and program memory separately. Data memory can be divided into 3 parts; 32 of common register, 64 of I/O register and 512 byte internal SRAM. For general purpose, the register is located in space data at the bottom address; from $\$ 00$ to $\$ 1 \mathrm{~F}$. Meanwhile, the special register to handle I/O data and control to the device is located in the next 64 address; from $\$ 20$ to $\$ 5 \mathrm{~F}$. The special register is actually to regulate the function of most microcontroller peripherals, such as register control, timer/counter, I/O functions, and so on. The remained address is used for SRAM 512 byte and located from $\$ 60$ to $\$ 25 \mathrm{~F}$. In addition, the program memory which is located inside the Flash PEROM is structured with 'word' or 2 byte for each instruction and its width of 16 or 32 bit. This type of microcontroller has 4Kbyter x 16 bit Flash PEROM and is addressed from $\$ 000$ to $\$ F F F$. Also, it has 12 bit counter program to address the Flash content. 


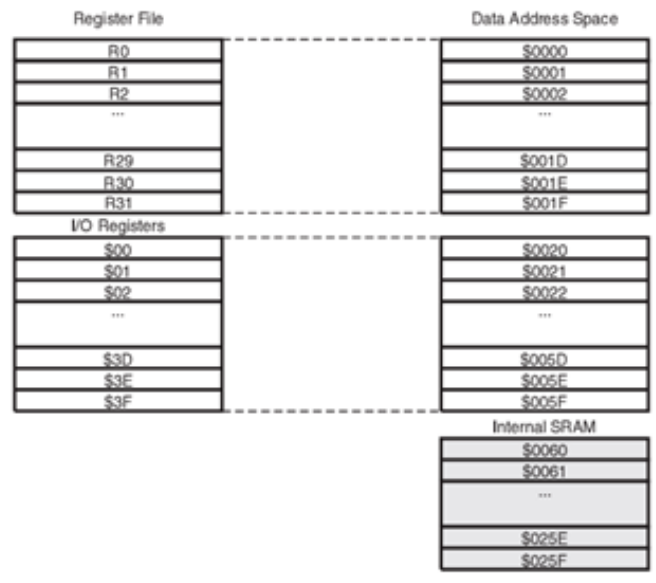

a. data memory

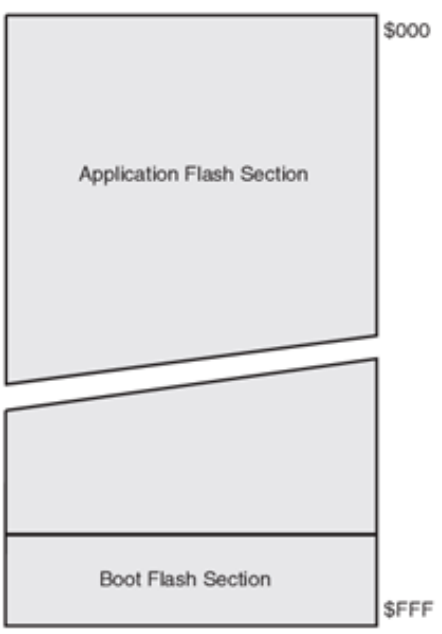

b. program memory

Figure 7. Data and program memory structure of microcontroller ATmega8535

In the proposed solar tracker design, the Code Vision AVR V2.03.4 software combined with $\mathrm{C}$ program is utilized as the compiler and program media editor. The Code Vision AVR software is commonly used for the functioning of AVR microcontroller type. Meanwhile, the C program is adapted with the Code vision AVR software, especially for some syntax programs in associated with register and memory access. In addition, the instruction in $\mathrm{C}$ program is conceptually similar and valid to the most syntax program in Code vision compiler.

\subsubsection{Actuator parabola}

The actuator parabola of Matrix Harl-3618 for dish satellite communication simply is used in the actuator to drive the PV module in the direction commanded by the microcontroller. The structure of this actuator parabola is shown in Figure 8. In our region, the type of actuator is easily found in the market with low price and it has simple structure. The actuator design is basically a dc motor connected to one axis that provides actuator movement, such as push and pulls an object. Moreover, the actuator construction is very strong within high efficiency and constant speed dc motor.

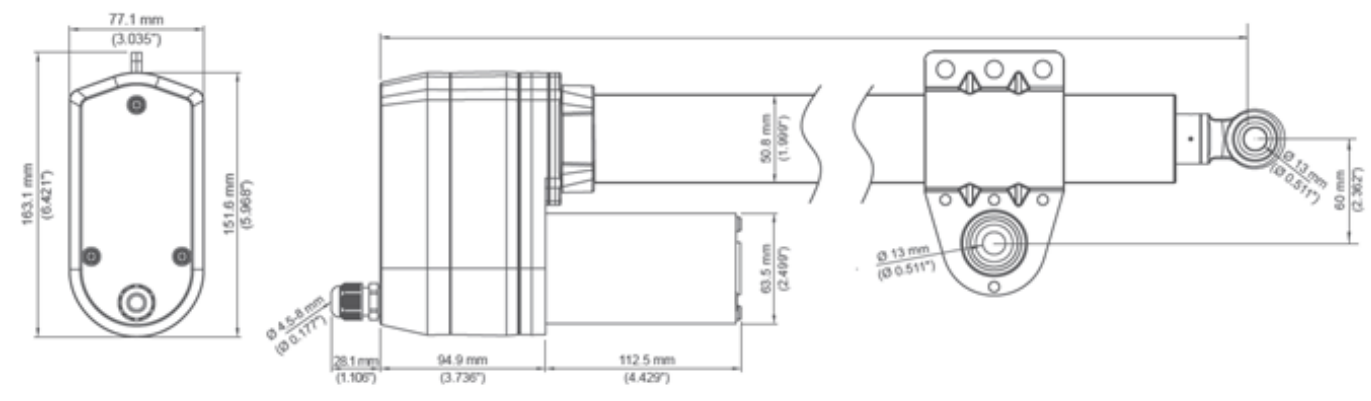

Figure 8. Schematic construction of actuator parabola 


\section{Hardware and Software Design of Solar Tracker}

There are two main configurations of basic design; hardware and software. In designing hardware, the focus is on the physical system design of solar tracking including electronic circuit. On the other hand, the software design consists of how to coordinate the movement of solar tracker according to the command from microcontroller. The main target of our proposed design is to drive the PV module $15^{\circ}$ perpendicular to the direction of sunlight for every one hour in the operating hour between 8a.m and 4p.m. The detail of hardware and software design is explained as follows.

The important point of the hardware design is the movement of actuator to direct the PV module in the correct orientation. The hardware configuration of complete solar tracker design is shown in Figure 9. In this figure, the PV module is horizontally installed in order to absorb as much as possible of sunlight. For this reason the PV module is supported with tilt $\mathrm{H}$-form, where the axis is made in the center to allow the movement of module according to the users' intention. Meanwhile, one edge of the actuator Matrix-Harl-36187 is permanently placed in the tilt-support in order to avoid displacement during the push-pull movement of PV module. The other edge of actuator is permanently connected to the PV module.

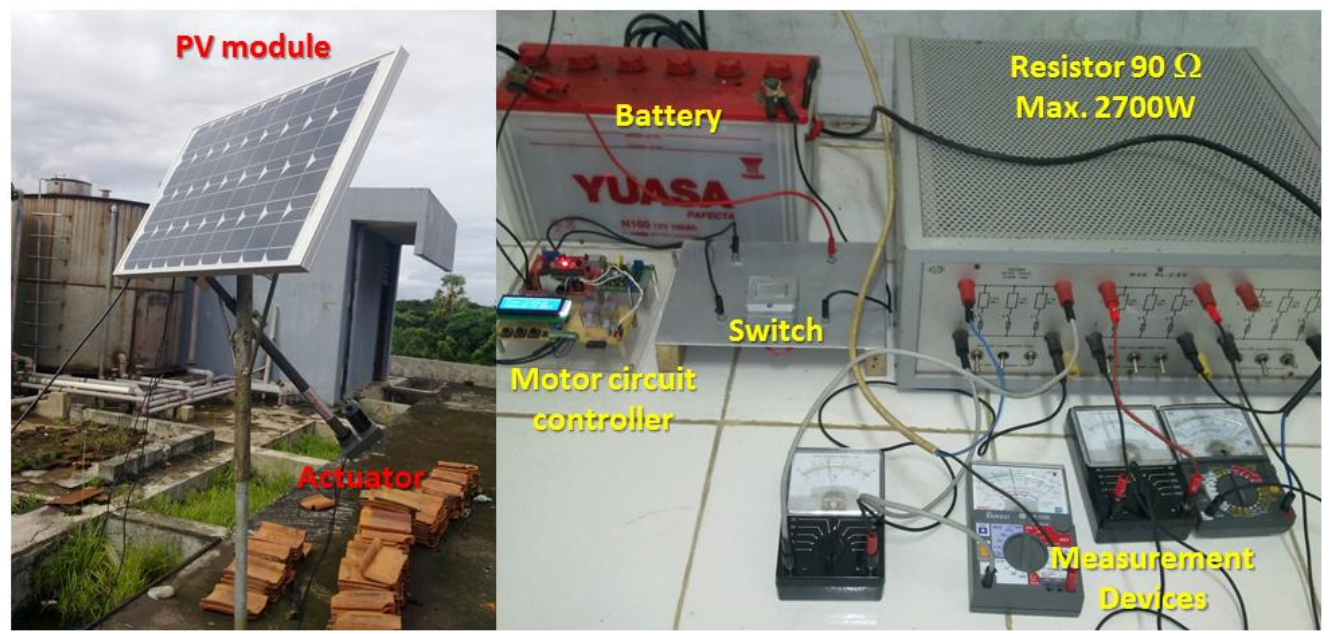

Figure 9. Configuration of solar tracker design

In one side of PV module, a small board with small mound is designed to connect to the limit switch. The board moves once the PV module moving. The small mound is arbitrarily created to represent the angle movement of PV module, which from $30^{\circ}$ (at 8 a.m) to $150^{\circ}$ (at 4 p.m). The actuator movement is limited by the limit switch. When the limit switches on; means the contactor changes from Normally Open (NO) to Normally Closed (NC), the PV module has reached the appropriate position. For instance, the microcontroller send instruction to the actuator to move the PV module at 10 a.m.; and at this time the limit switch changes from $\mathrm{NO}$ to $\mathrm{NC}$ at the $3^{\text {rd }}$ mound $\left(60^{\circ}\right)$, then actuator stops moving.

In the microcontroller circuit as shown in Figure 10, the IC RTC (SDA and SCL) connected the microcontroller ATmega8535 through PORTA.0 and PORTA.1, while the LCD connected through PORTC.0 to PORTC.7 (except PORTC.3). As results, the data send from IC RTC to the microcontroller can be displayed in the LCD. Meanwhile, the motor driver connected through PORTA.6 (for forward direction) and PORTA.7 (for reverse direction); limit switch connected through PORTD.0 and Ground (GND). 


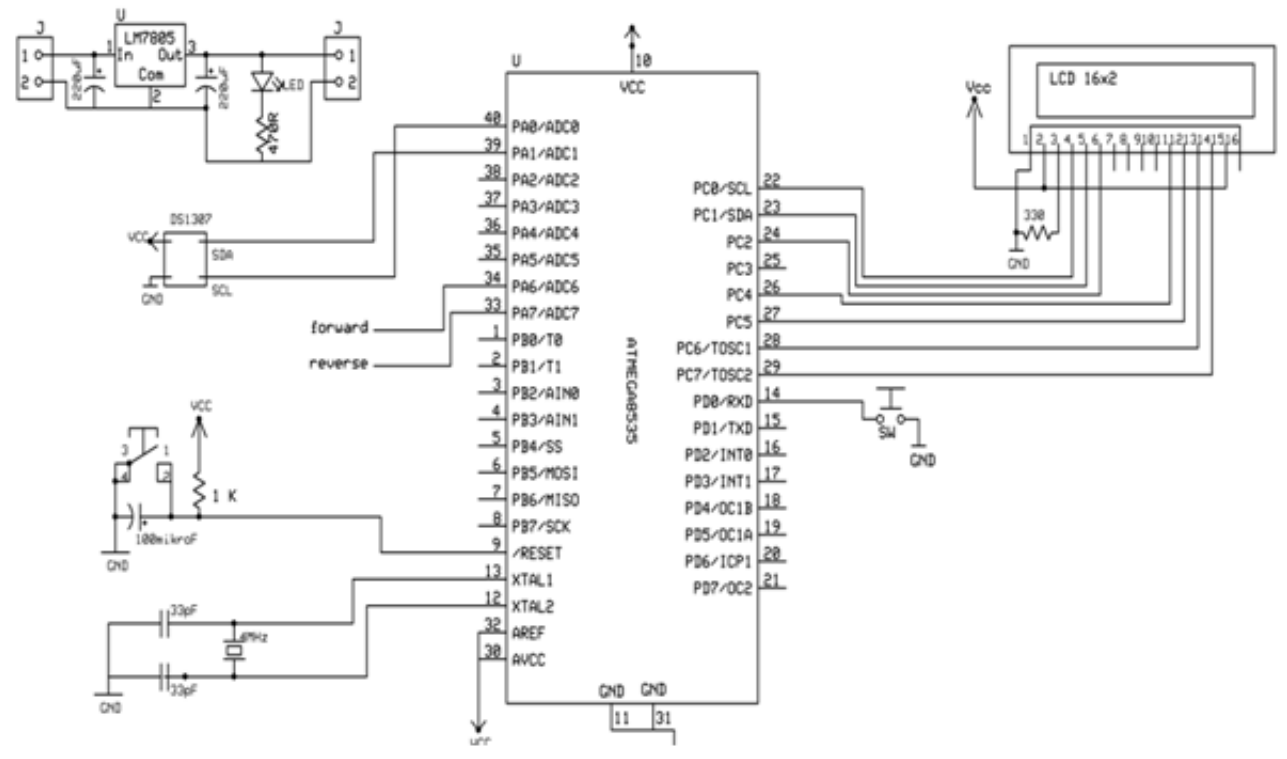

Figure 10. Microcontroller circuit for solar tracker

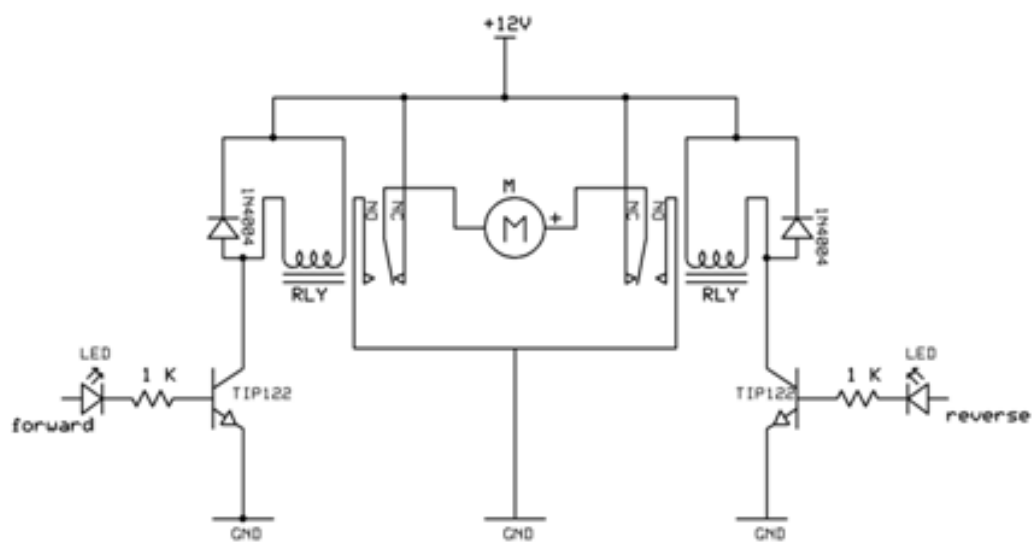

Figure 11. Driver motor circuit

For actuator/motor driver circuit in Figure 11, it can be seen that there are two relays with $12 \mathrm{Vdc}$ and their contactors connected to dc motor of actuator. The dc motor itself is connected to the Normally Closed (NC) of relay. Consequently, if one of the relays is not energized, then dc motor will not be experienced potential difference to run the motor. In addition, there are two resistors of $1 \mathrm{k} \Omega$ to bias the transistor TIP122 that works as automatic switch when the bias potential occurs. Meanwhile, the diode IN4004 is used to avoid unnecessary current entering the inductively coil of relay. Finally, the LED is an indicator for biased transistor and relay operates.

In associated with driver motor circuit in Figure 11 and the microcontroller circuit shown in Figure 10, the working principal of the complete actuator control circuit as depicted in Figure 12 are explained as follows. If the logic status of PORTA.6 is high and PORTA.7 is 
low then LED in the forward direction will on and transistor TIP122 is biased to make the coil relay being energized and the NC contactor status changes to be NO. As results, the dc motor is now supplied with potential difference of $12 \mathrm{Vdc}$ to drive the motor in forward direction or pushing the PV module. Conversely, if the logic status of PORTA.6 is low and PORTA.7 is high; then LED in the reverse direction will on to bias the transistor TIP122 in order to energize the coil of relay. As a result, the contactor changes the status from NC to NO and dc motor will be supplied by potential difference in the opposite direction. Consequently, the motor will run in reverse direction to pull the PV module.

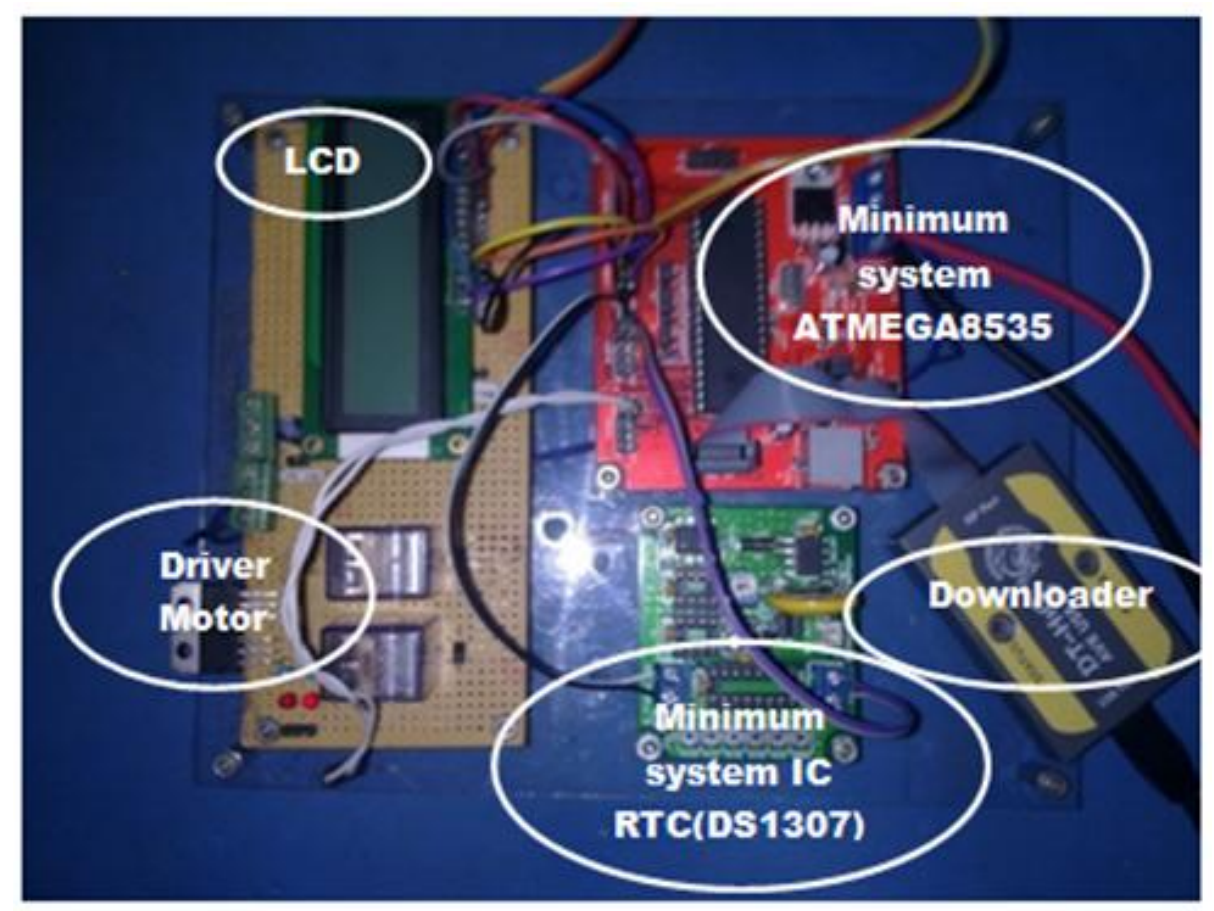

Figure 12. Complete actuator control circuit

The key point in software design is the algorithm to activate the $\mathrm{I} / \mathrm{O}$ port of microcontroller by changing the 'control word'. This step can be done by initializing of command in $\mathrm{I} / \mathrm{O}$, LCD and IC RTC. After the initialization, the program will read the data of date and hour in IC RTC and display them in LCD. Completing this step, the process in microcontroller will be in three different logic conditions. The first process is the microcontroller will display hour and date in the LCD under off condition. The second process is during the time interval between 8 a.m and 4 p.m. If the time display is exactly between 8 a.m and 4 p.m, the microcontroller will send signal to the actuator/dc motor to push the PV module (PORTA.6=1 and PORT A.7=0). However, if the limit switch operates (PORTD.0=1), then microcontroller will command the dc motor to stop. It means that the PV module has reached the appropriate orientation set by the users. After the time points to 4 p.m exactly, the microcontroller will command the dc motor to pull back the PV module by means to change the direction of motor rotation (PORTA.6 $=0$ and PORTA.7=1). Again, the microcontroller send signal to the actuator to stop once the limit switch completing 'high' logic condition for 8 times; means the PV module is now in the position similar at 8 a.m. 


\section{Testing Design in Real-time and Discussion}

Before presenting the testing results in real-time, it is important to show the technical specification of other component in photovoltaic system such as the PV module, charge controller, and battery. The specifications of module type, charge controller, and battery are presented in Table II, Table III and Table IV, respectively. Meanwhile the physical appearance of these devices is shown in Figure 13.

Table II. Technical specification of PV module

\begin{tabular}{ll}
\hline \multicolumn{1}{c}{ Technical Specification } & \multicolumn{1}{c}{ Technical rate } \\
\hline Type of PV module type & WJ50-M (Wika PV) \\
Rate maximum power & $50 \mathrm{~W}_{\mathrm{P}}$ \\
Tolerance & $\pm 5 \%$ \\
Rate operating voltage $\left(\mathrm{V}_{\mathrm{m}}\right)$ & $17.5 \mathrm{~V}$ \\
Rate operating current $\left(\mathrm{I}_{\mathrm{m}}\right)$ & $2.9 \mathrm{~A}$ \\
Operating circuit voltage $\left(\mathrm{V}_{\mathrm{oc}}\right)$ & $21.8 \mathrm{~V}$ \\
Short circuit current $\left(\mathrm{I}_{\mathrm{sc}}\right)$ & $3.3 \mathrm{~A}$ \\
Nominal operating cell temperature (NOCT) & $45^{\circ} \mathrm{C}$ \\
A M function & 1.5 \\
E (Irradiance) & $1000 \mathrm{~W} / \mathrm{m}^{2}$ \\
Cell temperature $\left(\mathrm{T}_{\mathrm{c}}\right)$ & $25^{\circ} \mathrm{C}$ \\
Maximum system voltage (connected in series) & $715 \mathrm{~V}$ \\
Wind resistance & $2400 \mathrm{~Pa}$ \\
Weight & $5 \mathrm{Kg}$ \\
Dimension & $845 \times 541 \times 30 \mathrm{~mm}$ \\
\hline
\end{tabular}

Table III. Technical specification of charge controller of SHS (EPHC-ST 10A 12/24V Auto)

\begin{tabular}{ll}
\hline \multicolumn{1}{c}{ Technical Specification } & \multicolumn{1}{c}{ Technical rate } \\
\hline Brand name/ Model number & OEM / EPHC-ST \\
Rated voltage & $12 / 24 \mathrm{~V}, 10 \mathrm{~A}$ (for PV module and load) \\
Maximum current & $10 \mathrm{~A}$ \\
Equalization voltage & $14.8 \mathrm{~V}$ \\
High voltage disconnect & $14.4 \mathrm{~V}$ \\
Float voltage & $13.6 \mathrm{Volt}$ \\
Low voltage disconnect & $11.1 \mathrm{~V}$ \\
Low voltage reconnect & $12.6 \mathrm{~V}$ \\
Self-consumption maximum & $6 \mathrm{~mA}$ \\
Temperature compensation & $-30 \mathrm{mV} /{ }^{\circ} \mathrm{C} / 12 \mathrm{~V}$ \\
Terminals & For wire sizes to $6 \mathrm{~mm}^{2}$ \\
Temperature & $-35{ }^{\circ} \mathrm{C}-+55^{\circ} \mathrm{C}$ \\
Dimension & $140 \mathrm{x} 90.5 \mathrm{~mm}$ \\
Compliance & $\mathrm{CE}$ \\
& \\
\hline
\end{tabular}


Table IV. Technical specification of battery

\begin{tabular}{lll}
\hline \multicolumn{1}{c}{ Technical Specification } & Technical rate \\
\hline Model & N100 & \\
C.C.A & 475 \\
Nominal voltage & $12 \mathrm{~V}$ \\
Capacity & $100(\mathrm{Ah})$ \\
Dimensions & $407 \times 173 \times 211 \mathrm{~mm}$ \\
Overall & $234(\mathrm{H})$ \\
Weight without acid approx. & $17.3 \mathrm{Kg}$ \\
Electrolyte approx. & $6.9 \mathrm{~A}$ \\
Regular charge current & 10.0 \\
Layout & 1 \\
Terminal & $\mathrm{A}$ \\
\hline
\end{tabular}

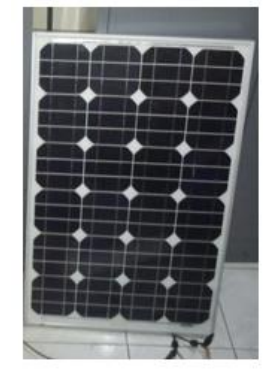

a. PV module

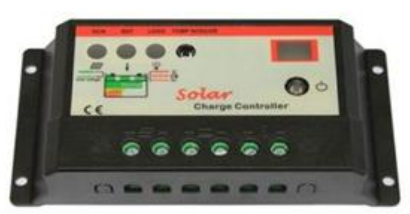

b. Charge controller

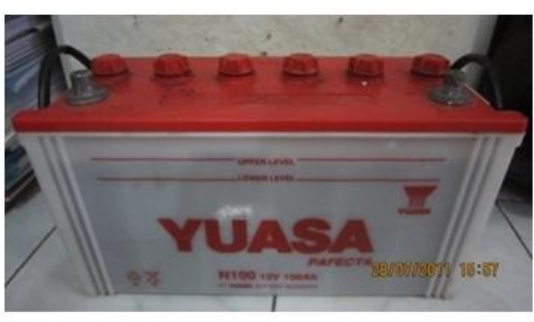

c. Battery

\section{Figure 13. The physical appearance of PV module, charge controller and battery in our proposed solar tracker design}

To convince the result of the proposed design, the scenario is set to compare the performance of solar tracker in terms of output power from PV module with the system without solar tracker (PV module with static condition under specific angle). Of course, both systems are located in the same place, very close to each other and are measured at the same time. The output power measurement is simply performed with connecting Voltmeter and Amperemeter in the output terminal where the load of $90 \square$ with the maximum output of $2700 \mathrm{~W}$ is connected.

The testing design is purposed to see how accurate our proposed solar tracker to drive the PV module perpendicular to the direction of sunlight. It has mentioned previously that the updating angle of solar tracker movement is $15^{\circ}$ per hour from 8 a.m to 4 p.m. In Table V, it is shown the comparison between the performances of solar tracker to the set angle theoretically from the mound setting in the board connected to the PV module, including the time of movement. It can be seen that the error position is relatively small after the steady operation of solar tracker about $1.5 \%$. The significant errors are only obtained just after starting and before stopping the solar tracker; $10 \%$ and $6.7 \%$, respectively. However, this is not discouraging the proposed solar tracker design in the correct movement as the software and hardware function properly. In terms of time duration, the movement of tracker from one position to the next position takes between half minute and minute. The critical time occurs when pushing the PV module horizontally; means the angle of $90^{\circ}$, consuming almost a minute due to the weight load of module. Also, it can be observed that our proposed solar 
tracker design is able to pushing back the PV module to original position ( 8 a.m) after the operating hours of 4 p.m.

Our solar tracker is successfully performed to rotate the PV module based on the targeted design. Now, we need to know how much the increasing in power of PV module achieved using this solar tracker in compared to the system without solar tracker. The PV system with solar tracker will be rotated automatically every 15 degree per hour from 8 a.m to 4 p.m based on the initial assumption of apparent movement of sunlight in equator region. As a result, the PV module will be perpendicular continuously to the direction of sunlight with simple actuator device. If the angle is arbitrarily changed, for instance 10 degree every hour, then the hardware needs to be modified. If the time interval movement is changed, then the microcontroller program is updated and so the hardware. In comparison to steady PV module (without solar tracker), the angle of module is constant of 45, 90 and 135 degrees to represent the sunlight position, such as just after sunrise, noon and before sunset respectively.

Table V. Comparison performance of solar tracker to the theoretical adjustment

\begin{tabular}{ccccc}
\hline \multirow{2}{*}{ Hour } & \multicolumn{2}{c}{ PV Module position } & \multirow{2}{*}{ Error (\%) } & \multirow{2}{*}{ time (s) } \\
\cline { 2 - 3 } & Mound setting & Solar Tracker & & \\
\hline 8a.m & $30^{\circ}$ & $27^{\circ}$ & $10 \%$ & 0 \\
\hline 9a.m & $45^{\circ}$ & $43^{\circ}$ & $4 \%$ & 26 \\
\hline 10a.m & $60^{\circ}$ & $59^{\circ}$ & $1.7 \%$ & 52 \\
\hline 11a.m & $75^{\circ}$ & $74^{\circ}$ & $1.3 \%$ & 35 \\
\hline 12a.m (noon) & $90^{\circ}$ & $89^{\circ}$ & $1.1 \%$ & 58 \\
\hline 1p.m & $105^{\circ}$ & $103^{\circ}$ & $1.9 \%$ & 33 \\
\hline 2 p.m & $120^{\circ}$ & $118^{\circ}$ & $1.7 \%$ & 42 \\
\hline 3 p.m & $135^{\circ}$ & $133^{\circ}$ & $1.4 \%$ & 29 \\
\hline 4 p.m & $150^{\circ}$ & $148^{\circ}$ & $1.3 \%$ & 18 \\
\hline After 4 p.m & $30^{\circ}$ & $28^{\circ}$ & $6.7 \%$ & 324 \\
\hline
\end{tabular}

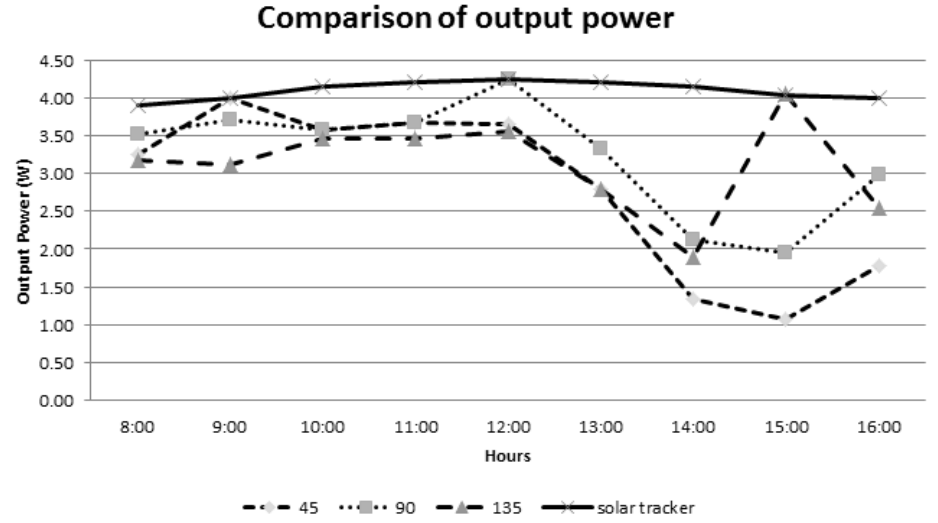

Figure 14. Output power between solar tracker based PV system and without solar tracker 
It can be seen from Figure 14 that the output power of the PV system with solar tracker is almost constant with the efficiency output about $8 \%$. In comparison, for the system without solar tracker (constant angle), is the output power tends decreasing once the sunlight passing the angle of module. For example, the constant angle of 45 degree means the PV module face the East, once the sunlight reaches noon to the sunset positions, the output power decreasing significantly. The same trend results are obtained for constant angle of 90 and 135 degree. Especially, for the constant angle of 135 degree, the module is directed to the afternoon position, means the output power in the morning and noon cannot be capitalized.

It is important to analyze the accumulative energy harvested during a year. The simulation can be performed using HOMER program for the location of Makassar city of Indonesia (5.14 South, 119.33 East) with NASA Surface meteorology and Solar Energy RETscreendata 2010. With the previous data calculation that single actuator is capable to move 45 number of PV modules, which means the PV system has total capacity of $2250 \mathrm{Wp}$. The energy accumulative obtained with the solar tracker system is around $5000 \mathrm{kWh} /$ year with the monthly average power production of $500 \mathrm{Wp}$. In comparison with the system without solar tracker, the energy accumulative is only around $4600 \mathrm{kWh} /$ year (monthly average power production of $400 \mathrm{Wp}$ ). It means that there are significant $400 \mathrm{kWh} /$ year obtained with the single design solar tracker. Of course, huge financial support is required to build PV farm requires. It is beyond our discussion. The point is the output power of PV system can be continuously reached, even though by developing very simple, cheaper solar tracker design systems.

\section{Conclusion}

The proposed design of solar tracker based microcontroller ATMega8535 combined with IC RTC timer is working optimally. The proposed system is claimed better than any other conventional horizontal based solar tracker system as follows. The energy consuming is very low $(2.961 \mathrm{Wh})$; therefore it can powered from the output of PV module for independent operation. We provide automatic feature reset after 4 p.m to pull back the PV module to the position of 8 a.m and waiting the next day operation. This feature increases the efficiency operation of system. The materials and components can be easily found in the market with low price and constructed without having special knowledge for design. The solar tracker can be used to rotate group of PV module or heliostat due to the capability of actuator to push a maximum load to about $600 \mathrm{lbs}$ or $272.4 \mathrm{~kg}$. If the total weight of PV module and its support system is $6 \mathrm{~kg}$, then this actuator can rotate massive of 45 number of PV modules located in single axis. Because of using microcontroller based technology, the proposed design is adapted to almost all telecommunication networks, such as coaxial cable, cellular and internet networks. This feature is very important since the PV farm or heliostat for solar thermal power plant is located in remote area and their control process is centrally performed. With their features, the proposed solar tracker design is feasible implemented in any regions. The testing results show that the accumulative energy capturing annually for $2250 \mathrm{Wp}$ of PV system with solar tracker is about $5000 \mathrm{kWh}$, which is higher to the one without solar tracker, which is only $4600 \mathrm{kWh}$. One can imagine that the energy harvesting becomes significantly if the number of modules increase in a photovoltaic farm.

\section{References}

[1] G. M. Tina, S. Gagliano, G. Graditi and A. Merola, "Experimental validation of a probabilistic model for estimating the double axis PV tracking energy production", Applied Energy, doi.10.1016/j.apenergy.2012.01.054. 
[2] C. Furlan, A. P. de Oliveira, J. Soares, G. Codato and J. F. Escobedo, "The role of clouds in improving the regression model for hourly values of diffuse solar radiation”, Applied Energy, vol. 92, (2012) April, pp. 240-254.

[3] G. Notton, C. Paoli, S. Vasileva, M. L. Nivet, J. -L. Canaletti, C. Cristofari, "Estimation of hourly global solar irradiation on tilted planes from horizontal one using artificial neural networks", Energy, vol. 39, Issue 1, (2012) March, pp. 166-179.

[4] S. R. Wenham, M. A. Green, M. E. Watt and R. Corkish, in Applied Photovoltaics (Second Edition), Earthscan Publications Ltd., London, UK, (2007).

[5] Syafaruddin, E. Karatepe and T. Hiyama, "Fuzzy wavelet network identification of optimum operating point of non-crystalline silicon solar cells", Computers and Mathematics with Applications, vol. 63, (2012), pp. 6882.

[6] T. Mishima, M. Taguchi, H. Sakata and E. Maruyama, "Development status of high-efficiency HIT solar cells", Solar Energy Materials and Solar Cells, vol. 95, Issue 1, (2011) January, pp. 18-21.

[7] X. Gu, X. Yu, K. Guo, L. Chen, D. Wang and D. Yang, "Seed-assisted cast quasi-single crystalline silicon for photovoltaic application: Towards high efficiency and low cost silicon solar cells", Solar Energy Materials and Solar Cells, vol. 101, (2012) June, pp. 95-101.

[8] M. Yamaguchi, K.-I. Nishimura, T. Sasaki, H. Suzuki, K. Arafune, N. Kojima, Y. Ohsita, Y. Okada, A. Yamamoto, T. Takamoto and K. Araki, "Novel materials for high-efficiency III-V multi-junction solar cells", Solar Energy, vol. 82, Issue 2, (2008) February, pp. 173-180.

[9] E. Díaz-Dorado, A. Suárez-García, C. J. Carrillo and J. Cidrás, "Optimal distribution for photovoltaic solar trackers to minimize power losses caused by shadows", Renewable Energy, vol. 36, Issue 6, (2011) June, pp. 1826-1835.

[10] A. Woyte, J. Nijs and R. Belmans, "Partial shadowing of photovoltaic arrays with different system configurations: literature review and field test results", Solar Energy, vol. 74, Issue 3, (2003), pp. 217-233.

[11] E. Karatepe, Syafaruddin and T. Hiyama, "Simple and high efficiency photovoltaic system under nonuniform operating conditions", IET Renewable Power Generation, vol.4, Issue 4, (2010), pp. 354-368.

[12] T. Esram and P. L. Chapman, "Comparison of photovoltaic array maximum power point tracking techniques", IEEE Transactions on Energy Conversion, vol. 22, (2007), pp. 439-449.

[13] F. R. Rubio, M. G. Ortega, F. Gordillo and M. López-Martínez, "Application of new control strategy for sun tracking”, Energy Conversion and Management, vol. 48, Issue 7, (2007) July, pp. 2174-2184.

[14] T. Maatallah, S. El Alimi and S. B. Nassrallah, "Performance modeling and investigation of fixed, single and dual-axis tracking photovoltaic panel in Monastir city, Tunisia", Renewable and Sustainable Energy Reviews, vol. 15, Issue 8, (2011) October, pp. 4053-4066.

[15] M. J. Clifford and D. Eastwood, "Design of a novel passive solar tracker", Solar Energy, vol. 77, Issue 3, (2004) September, pp. 269-280.

[16] H. Mousazadeh, A. Keyhani, A. Javadi, H. Mobli, K. Abrinia and A. Sharif, "A review of principle and suntracking methods for maximizing_solar systems output", Renewable and Sustainable Energy Reviews, vol. 13, Issue 8, (2009) October, pp. 1800-1818.

[17] B. J. Huang, W. L. Ding and Y. C. Huang, "Long-term field test of_solar PV power generation using one-axis 3-position sun tracker", Solar Energy, vol. 85, Issue 9, (2011) September, pp. 1935-1944.

[18] S. Abdallah and O. O. Badran, "Sun tracking system for productivity enhancement of solar still", Desalination, vol. 220, Issues 1-3, (2008) March 1, pp. 669-676.

[19] J. Randolph, et al., in Energy for Sustainability: Technology, Planning, Policy, Island press, (2008). 